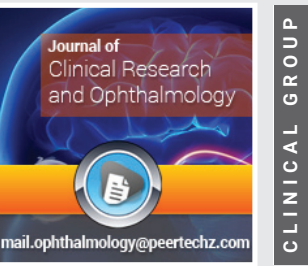

\title{
Overlap Syndrome: A case with features of both Sturge Weber and klippel trenaunay phacomatoses
}

\author{
Nischala Balakrishna ${ }^{1 *}$ and Seema Channabasappa ${ }^{2}$ \\ 1Junior Resident, Department of Ophthalmology, Vydehi Institute of Medical Sciences and Research \\ Centre, Bangalore, India \\ ${ }^{2}$ Professor, Department of Ophthalmology, Vydehi Institute of Medical Sciences and Research Centre \\ Bangalore, India
}

Received: 16 February, 2020
Accepted: 30 March, 2020
Published: 31 March, 2020

*Corresponding author: Dr. Nischala Balakrishna, Junior Resident, Department of Ophthalmology, Vydehi Institute of Medical Sciences and Research Centre, Bangalore, Number 96, First Main Road Seshadripuram, Next To Sri Chaitanya Techno Schools, Bangalore560020, India, Tel: +91 8762558431; 8217352997; E-mail: nischalabalakrishna@gmail.com

Keywords: Sturge weber; Klippel trenaunay; Phacomatoses; Nevus flammeus; Choroidal haemangioma

https://www.peertechz.com

\section{Check for updates}

\begin{abstract}
Background: Sturge Weber and Klippel Trenaunay syndromes are mesodermal phacomatoses occurring sporadically. We report a rare case with overlapping features of both syndromes.

Case report: An eight-year-old girl complains of low vision and pain in left eye for nine months. Examination revealed port wine stain on left side of face, fingertips and toes present since birth. Length of both legs was symmetrical with skin hypertrophy. Visual acuity was light perception and lid swelling with hyphema noticed in left eye. BScan showed retinal detachment with choroidal haemangioma. CT scan showed orbital inflammation. The haemangioma was treated with Intravitreal Bevacizumab followed by vitrectomy with subretinal fluid drainage and focal laser. Radiotherapy was given to the left orbit.
\end{abstract}

Conclusion: Nevus flammeus, choroidal haemangioma, retinal detachment and neovascular glaucoma consistent with Sturge Weber syndrome. Soft tissue hypertrophy with dilated veins is compatible with Klippel Trenaunay syndrome.

\section{Introduction}

Sturge-Weber syndrome (OMIM ENTRY-185300) is a mesodermal phacomatosis which is characterized by port-wine vascular nevus on the of the face, leptomeningeal angiomatosis and choroidal lesions associated with glaucoma as these are mostly of vascular aetiologies. These patients also have seizures, neurologic deterioration and developmental delay [1]. Klippel-Trenaunay syndrome (OMIM ENTRY- 149000) also, a mesodermal phacomatosis is characterized by a triad of features. It includes vascular malformations like venous varicosities and hyperplasia of soft tissues of the affected limb [2]. Both the syndromes occur sporadically. Although extremely rare, Patients with overlapping features of SturgeWeber syndrome and Klippel-Trenaunay syndrome have been reported [3,4]. We report here an unusual case of an eight- year-old girl with overlapping features of both Sturge-Weber syndrome and Klippel Trenaunay syndrome.

\section{Case report}

An eight-year-old girl from Howrah, Kolkata, India with Klippel Trenaunay syndrome presented to the Ophthalmology department of Vydehi Institute of Medical Sciences and Research Centre with complaints of low vision, pain and redness in the left eye for nine months (Figure 1). The girl was born to non-consanguineous parents and had no other siblings. Her best corrected visual acuity was $6 / 6$ in the right eye and Perception of light in the left eye. Anterior segment examination revealed the right eye to be within normal limits and left eye with lid swelling with complete hyphema and conjunctival congestion. B Scan showed funnel shaped retinal detachment with thickened choroid with normal optic nerve 
head (Figure 2). Fundus findings were consistent with the $\mathrm{B}$ scan findings in the left eye while the right eye was normal (Figures 3,4). According to the history obtained from her parents, she was born following an uncomplicated vaginal delivery. The parents reported a purple coloured congenital cutaneous vascular malformation on her face which she had since birth. Family history was negative for Klippel Trenaunay syndrome, Sturge Weber syndrome and other phacomatoses. During the physical examination, port wine stains were noted over the left side of her face, finger tips and left toes. She had an asymmetric face and the left side of the face was swollen. Although she had skin hypertrophy, length of both legs was symmetrical. Teeth and hair were appearing normal. Cervical lymph node enlargement was present on palpation of lymph nodes. The remaining general and neurological examinations were within normal limits. Psychomotor development was apparently normal and ECG, Chest x-ray, leg and hand x-rays, abdominal and pelvic ultrasound examinations were normal. CT Scan shows Left globe enlarged. Majority of posterior

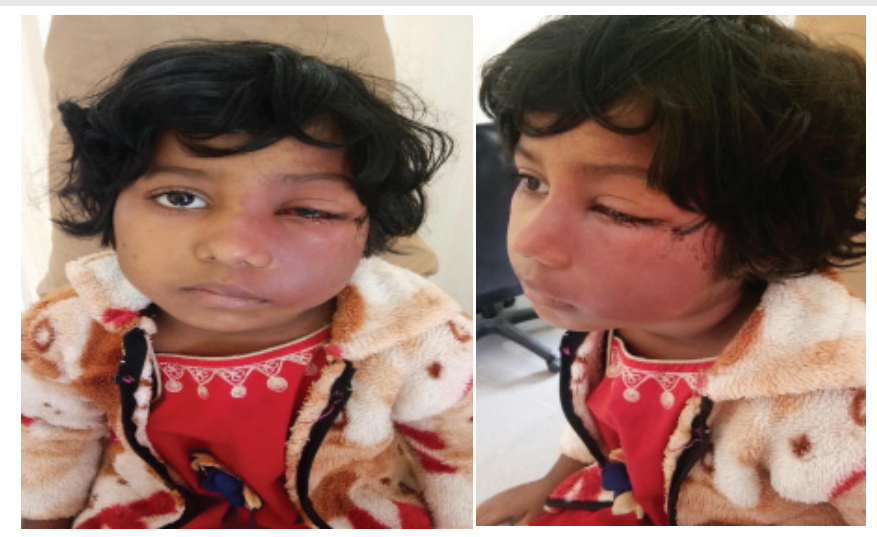

Figure 1: A large port wine stain can be seen on the left side of the face. The stain has caused facial asymmetry and has also involved the globe causing a decrease in visual acuity.

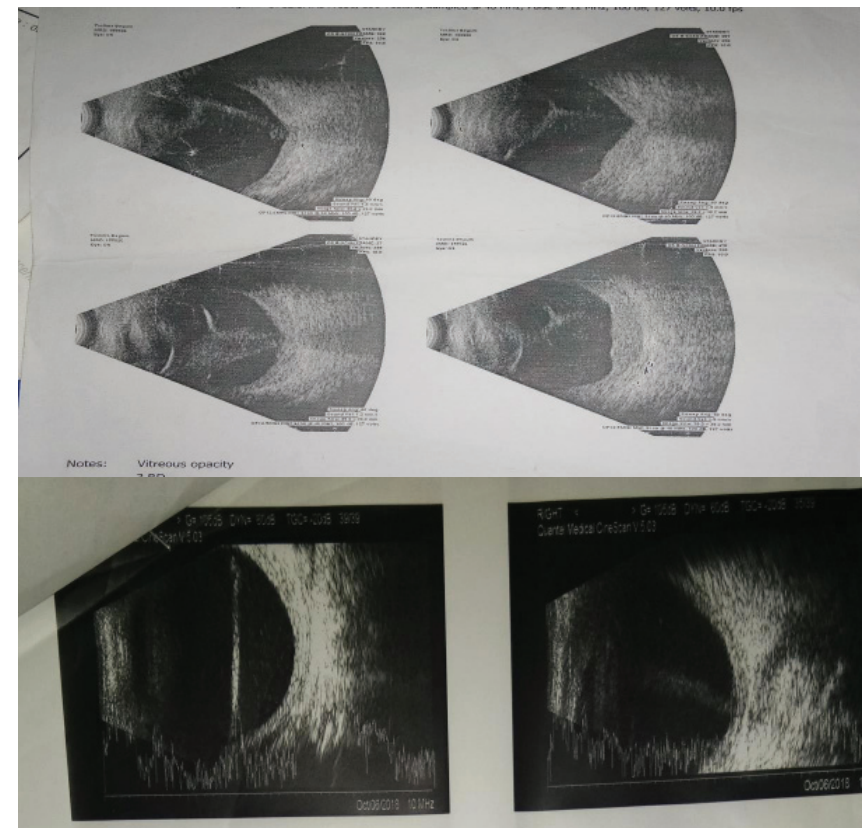

Figure 2: B Scan showed funnel shaped retinal detachment with thickened choroid (choroidal haemangioma) with normal optic nerve head.

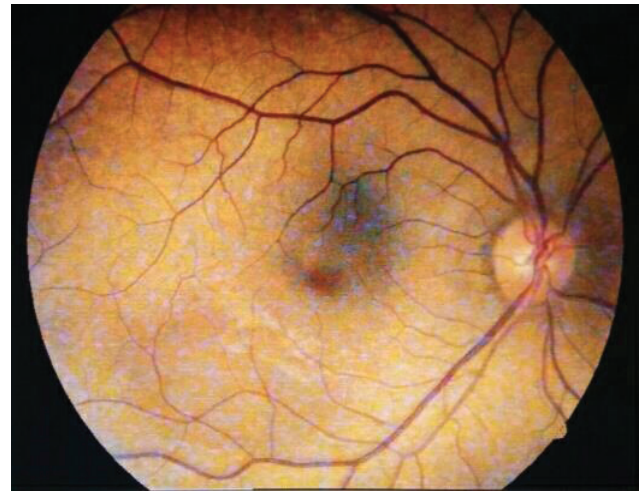

Figure 3: Right eye fundus is normal.

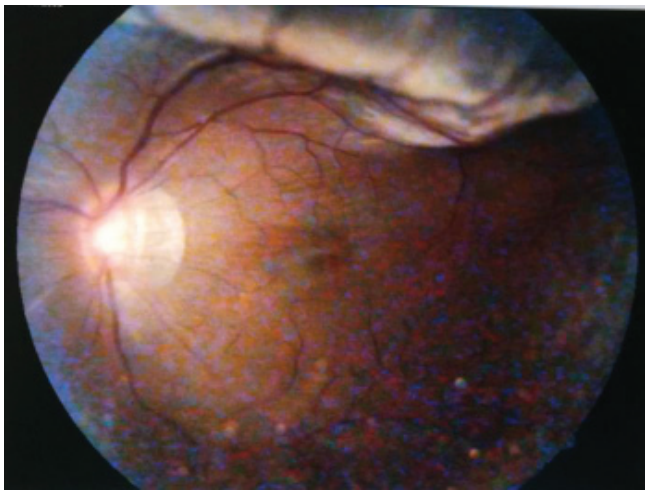

Figure 4: Left eye showing a retinal detachment with neovascular glaucoma and choroidal haemangioma.

segment of left eye is filled with non-enhancing hyperdense fluid with $\mathrm{V}$ shaped anterior margin-features suggestive of complete retinal detachment with hyperdense sub retinal fluid. Left idiopathic orbital inflammation (pseudotumor) (Figures 5,6). Patient underwent vitrectomy with SRF drainage with focal laser treatment to haemangioma with injection Avastin and was given EBRT (2500 CGY) in 14 fractions Left orbit by VMAT technique. The post-operative vision after three months in the left eye had improved to 6/36.The child was visually and symptomatically better.

\section{Discussion}

Sturge Weber syndrome is a relatively rare neurocutaneous disease ${ }^{5}$. The classical Klippel Trenaunay syndrome was first described by Klippel and Trenaunay in $1900[6,7]$. Most cases are associated with somatic mutations associated with genes involved in embryonic vasculogenesis and angiogenesis [8-10]. It was Schnyder, et al. [11], who first bridged the gaps between both these syndromes. It was suggested that both these were only variants and the common feature amongst them were haemangiomas and local gigantism. Epileptic fits and choroidal haemangioma or glaucoma are suggestive of Sturge Weber Syndrome. Local gigantism with osteohypertrophy and haemangioma of the limbs present as Klippel-Trenaunay syndrome. It suggests that the basic pathology of these two syndromes are the same but with different presentations. The remaining characteristics of these syndromes are thought to be secondary to the involvement of the neuro-ectodermal vasculature. 


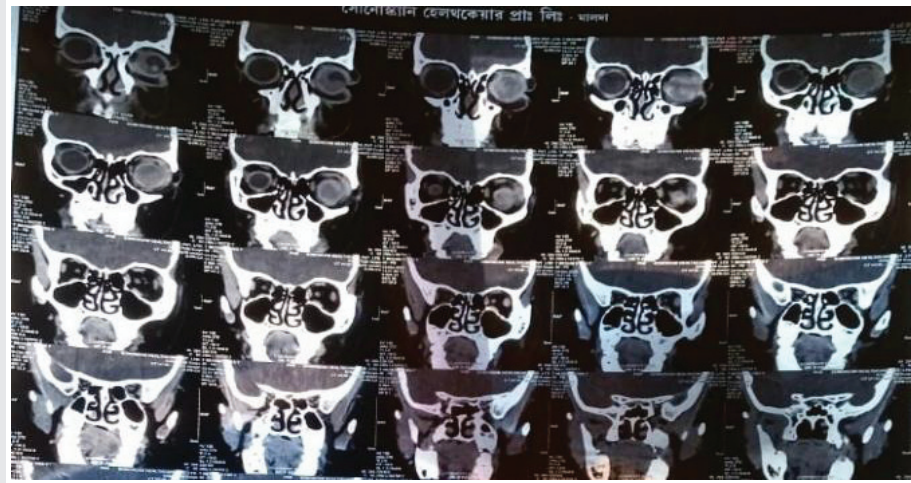

Figure 5: Shows the sagittal cuts on CT Scan where the left globe is enlarged. Majority of the posterior segment of the left eye is filled with non-enhancing hyperdense fluid with $\mathrm{V}$ shaped anterior margin suggestive of complete retinal detachment with hyperdense sub retinal fluid.

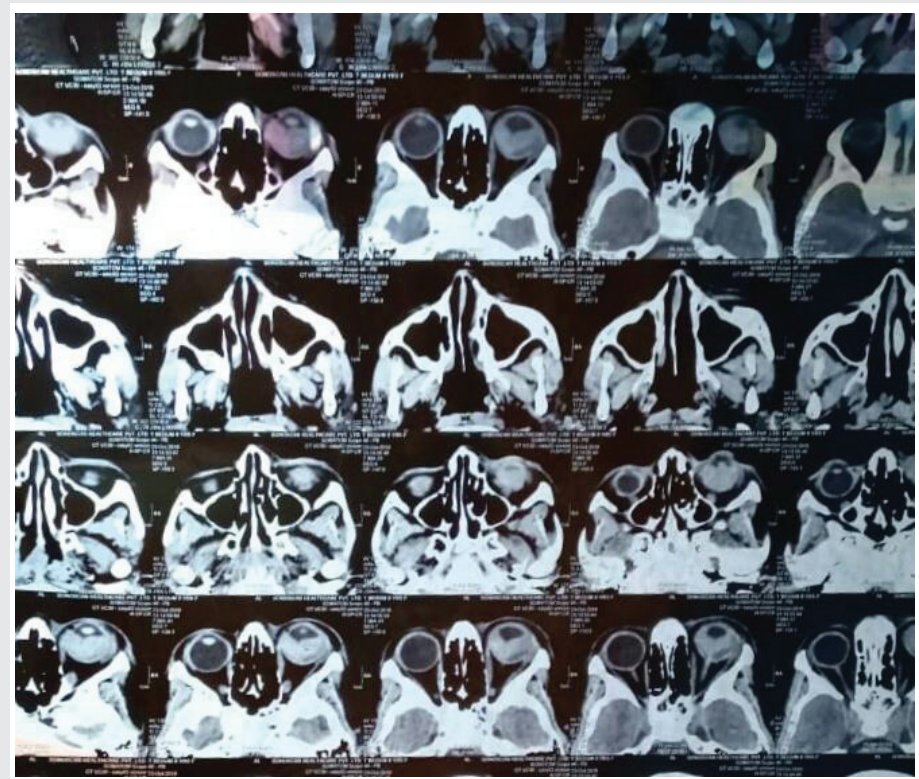

Figure 6: Shows the axial cuts of the CT Scan where the left globe is enlarged and filled with non-enhancing hyperdense fluid.

\section{Conclusion}

Our patient presented with nevus flammeus on the left side of the face, finger tips and left toes, choroidal haemangioma with retinal detachment with mild vitreous haemorrhage with neovascular glaucoma in the left eye which were consistent with Sturge Weber syndrome. She also had soft tissue hypertrophy of the left leg along with dilated superficial veins of the affected limb, which were compatible with Klippel Trenaunay syndrome. The uniqueness of this case is that the child has overlapping features of both syndromes which is a rare entity. Sporadic cases with such overlapping features have been reported [3,4,12,13].

\section{Consent}

Informed consent was obtained from the patient and the guardian for publication of this case report and accompanying images

\section{Ethical approval}

The study was performed with the informed consent and following all the guidelines for experimental investigations required by the institutional review board or ethics committee of which all authors are affiliated.

\section{References}

1. Sturge WA (1879) A case of partial epilepsy apparently due to a lesion of one of the vasomotor centers of the brain. Trans Clin Soc Lond 12: 162-167. Link: https://bit.ly/2U06VyL

2. Barek L, Ledor S, Ledor K (1982) The Klippel-Trenaunay syndrome: A case report and review of the literature. Mt Sinai J Med 49: 66-70. Link: https://bit.ly/341EBNI

3. Deutsch J, Weissenbacher G, Widhalm K, Wolf G, Barsegar B (1976) Combination of the syndrome of the Sturge-Weber and the syndrome of Klippel-Trenaunay. Klin Pediatr 188: 464-471. Link: https://bit.ly/33YOnA2

4. Lee CW, Choi DY, Oh YG, Yoon HS, Kim JD (2005) An Infantile Case of SturgeWeber Syndrome in Association with Klippel-Trenaunay-Weber Syndrome and Phakomatosis Pigmentovascularis. J Korean Med Sci 20: 1082-1084. Link: https://bit.ly/2UUv1rQ

5. Haslam Robert HA (2008) Sturge-Weber disease. In: Behrman RE, Kliegman RM, Jenson HB, Stanton BF, editors. Nelson's Textbook of Pediatrics. 18th ed. Philadelphia: Saunders 2487. Link: https://bit.ly/2yjvl69

6. Garzon MC, Huang JT, Enjolras O, Frieden IJ (2007) Vascular malformations Part II: Associated syndromes. J Am Acad Dermatol 56: 541-564. Link: https://bit.ly/2UNwwYB

7. Madaan V, Dewan V, Ramaswamy S, Sharma A (2006) Behavioura manifestations of sturge-weber syndrome: A case report. J Clin Psychiatry 8 198-200. Link: https://bit.ly/2WUSP1b

8. Timur AA, Driscoll DJ, Wang Q (2005) Biomedicine and diseases: The KlippelTrenaunay syndrome, vascular anomalies and vascular morphogenesis. Cell Mol Life Sci 62: 1434-1447. Link: https://bit.ly/2wHufq2

9. Tian XL, Kadaba R, You SA, Liu M, Timur AA, et al. (2004) Identification of an angiogenic factor that when mutated causes susceptibility to KlippelTrenaunay syndrome. Nature 427: 640-645. Link: https://bit.ly/2JnlUt8

10. Schnyder UW, Landolt E, Martz G (1956) Syndrome de Klippel-Trenaunay avec colombe irien atypique. J Genet Hum 5: 1-8.

11. Purkait R, Samanta T, Sinhamahapatra T, Chatterjee M (2011) Overlap of sturge-weber syndrome and klippel-trenaunay syndrome. Indian J Dermatol 56: 755-757. Link: https://bit.ly/2JDMijP

12. Kentab AY (2016) Klippel-Trenaunay and Sturge- Weber overlapping syndrome in a Saudi boy. Sudan J Paediatr 16: 86-92. Link: https://bit.ly/2QYGCor

13. Purkait R, Samanta T, Sinhamapatra T, Chatterjee M (2011) Overlap of SturgeWeber Syndrome and Klippel-Trenaunay Syndrome. Indian J Dermatol 56: 755757. Link: https://bit.ly/2JDMijP

Copyright: @ 2020 Balakrishna N, et al. This is an open-access article distributed under the terms of the Creative Commons Attribution License, which permits unrestricted use, distribution, and reproduction in any medium, provided the original author and source are credited. 